\title{
Fair pricing or pricing for profit?
}

\author{
Cite as: CMAJ 2017 May 23;189:E733-4. doi: 10.1503/cmaj.1095429
}

$f$ you had $\$ 500000$, would you provide drugs to one person who has a rare disease for a year, cure ten people of hepatitis $\mathrm{C}$, or treat 500 with diabetes? This sort of question is plaguing cashstrapped public pharmacare programs in Canada.

What is fair pricing? It's a question making headlines and prompting debate, such as at a panel discussion at the recent 2017 Canadian Agency for Drugs and Technologies in Health Symposium. What was billed as a two-person panel on fair drug pricing swelled to six. Every chair was filled and people lined the walls. At stake are big dollars and sustainability.

The global market for drugs is expected to reach US\$1.5 trillion by 2021 , a $33 \%$ increase in five years, said Tanya Potashnik, director of policy and economic analysis at Canada's Patented Medicines Prices Review Board (PMPRB). "Sustainability, access and continued ability for governments to find funding for pharmaceuticals is highlighted in that [increase]."

The cost crunch is arguably worse in Canada, where prices are about $28 \%$ higher than the international average, according to Potashnik. "And our R\&D [research and development] is below countries that even have much lower prices than us."

Prime Minister Justin Trudeau has delivered a mandate letter to the minister of health asking her to look at the question of drug affordability.

It's fair for industry to make a profit, but "more transparency is an issue on how prices are derived," said Potashnik. "We have no transparency into the R\&D costs. We've seen studies that estimate $\$ 180$ million to $\$ 2.5$ billion. That's a fairly significant range."

The pharmaceutical industry was represented at the panel by Mark Legault, Pfizer Canada's director of market access and strategic pricing. He stressed that "Canada has a fair pricing regime."
"Holistic reform" is not needed, he said. The answer, "if you level the facts out, might very well be we're almost there, but there are a couple of areas where we need to investigate and dig a little bit."

Those areas might include the complicated interplay of price and cost, fairness in prices post-patent, and products without comparators. He provided few details on the first two, but focused on the latter questioning the need for "heavy regulations to ensure fairness."

That's not where Eric Lun focused his attention. The executive director of drug intelligence and optimization with the British Columbia Ministry of Health is faced with a flat-lined budget, escalating prices and difficult decisions like the one that began this article.
"When you have a tight budget, you have to be very selective. When you make a decision on one, you will not be able to pay for something else," said Lun. "When we see these prices, we do question: Where did this price come from? Is it return on investment [ROI]? Or cost effectiveness?...It is about profit maximization. It's a combination of things; we just don't have the clarity there," he said. "We've never actually seen the real numbers that may actually go into ROI for these types of drugs."

He put forward a few "wild ideas" for addressing the problem, including industry and government codeveloping products. Or we could maximize price caps, and "give regulatory agencies authority to deal with unfair and excessive pricing," Lun said.

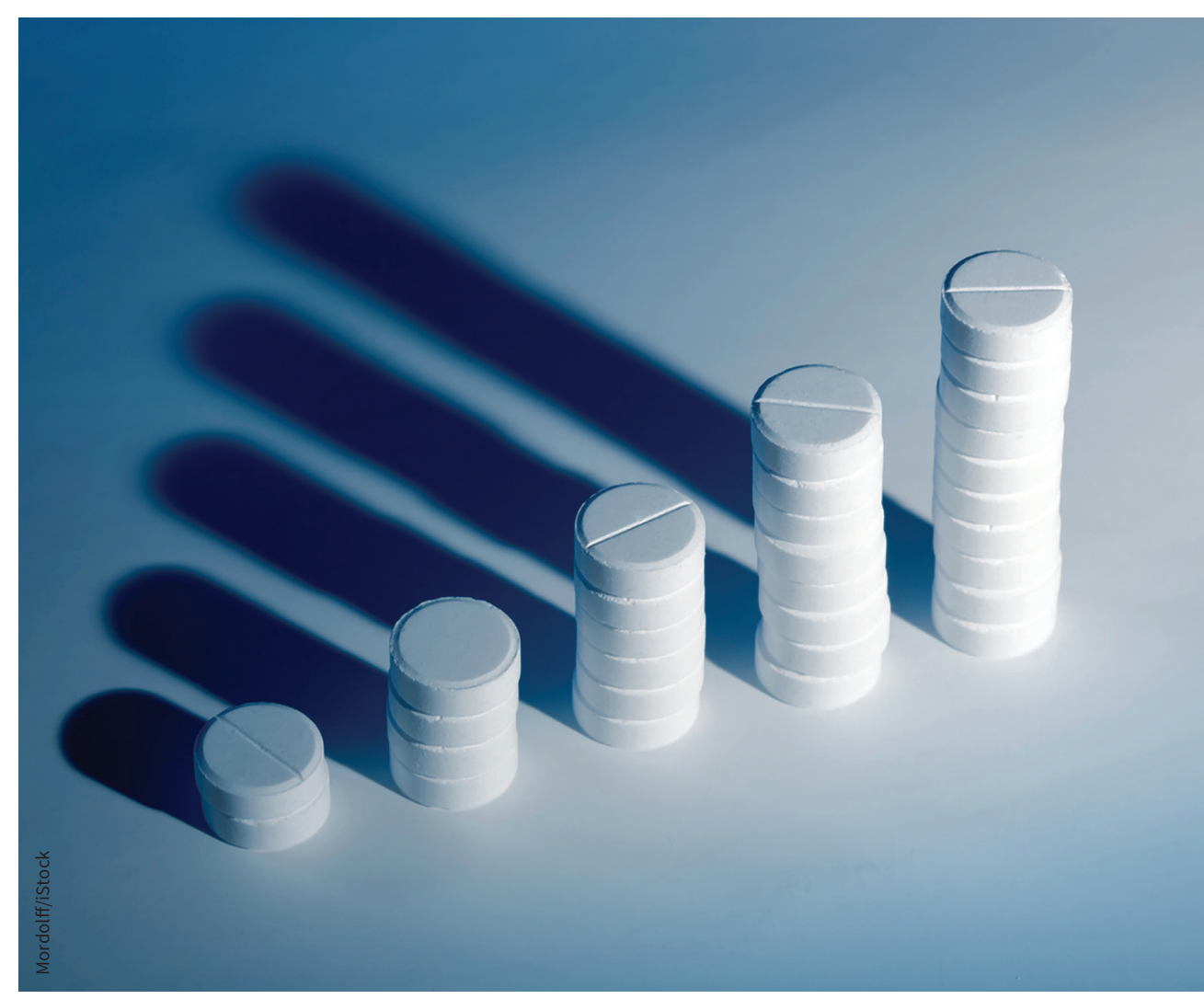

Governments face hard decisions given rising drug prices. 
"Our current mechanisms are not working very well," he concluded. "We do need to work together to solve this."

That collaborative approach might include patients such as panelist Linda Wilhelm, president of the Canadian Arthritis Patient Alliance, who has lived with rheumatoid arthritis for 35 years. She argues that the high price of new drugs is offset by savings in hospital costs, as well as restored productivity.

When more effective biologics arrived in 1999, they "were the highest-cost drugs anyone had ever seen," Wilhelm said. Over ten years, her drug, Enbrel (etanercept), cost $\$ 150$ 000. Over that same period, she calculated that hospitalizations and other care would have cost taxpayers $\$ 500000$.

"It seems to be fair to pay $\$ 500000$ in hospital costs and surgery costs...but not to spend $\$ 150000$ on a drug," she said. "Who has been tracking the cost savings of that? I don't think anyone has."

Fair pricing must also take into consideration new therapies that cure, rather than treat, a disease. New drugs for hepatitis C, for example, have a $90 \%$ cure rate, which could save the health system a lot of money, said Rob Boyd of Action Hepatitis Canada. "So the cost of the drug should be high, but what it doesn't take into account is prevalence."

An estimated 250000 Canadians harbour the hepatitis $\mathrm{C}$ virus. "New guidelines recommend not screening, and the main reason is because of pricing." It's unfair and unethical to screen somebody who you are not going to be treating afterward," said Boyd.

"Is our drug pricing framework built to handle cures?" he asked.

Barbara Sibbald, CMAJ 